\title{
Resin Bonding to Silicatized Zirconia with Two Isocyanatosilanes and a Cross-linking Silane. Part I: Experimental
}

\author{
Christie Y. K. Lung • Jukka P. Matinlinna
}

Received: 15 April 2010 /Accepted: 19 May 2010 /Published online: 8 June 2010

(C) The Author(s) 2010. This article is published with open access at Springerlink.com

\begin{abstract}
In this study we have investigated the effects of the chain length of hydrolyzable groups in two isocyanato silane coupling agents, 3-isocyanatopropyltrimethoxysilane and 3isocyanatopropyltriethoxysilane, on the shear bond strength of resin attached to silicatized zirconia. In addition, the effects of varying the silane concentration (at $0.1 \mathrm{vol} \%$ and $1.0 \mathrm{vol} \%$ ) with or without the addition of a cross-linking silane ( $0.05 \mathrm{vol}$ $\%$ or $0.5 \mathrm{vol} \%$ bis-1,2-(triethoxysilyl)ethane) were assessed. It was concluded that the use of the experimental primer of 3-isocyanatopropyltrimethoxysilane at either $0.1 \mathrm{vol} \%$ or 1 vol\% with cross-linking silane resulted in significantly higher shear bond strengths than the use of primer without the cross-linking silane.
\end{abstract}

Keywords Silane $\cdot 3$-isocyanatopropyltrimethoxysilane . 3-isocyanatopropyltriethoxysilane $\cdot$ bis-1,2-(triethoxysilyl) ethane) - 3-methacryloxypropyltrimethoxysilane ·

Cross-linking $\cdot$ Hydrolyzable group $\cdot$ Zirconia

\section{Introduction}

Zirconia (zirconium dioxide, $\mathrm{ZrO}_{2}$ ) is used in dentistry and is doped with a small amount of yttria $\left(\mathrm{Y}_{2} \mathrm{O}_{3}\right)$ tetragonal zirconia polycrystal (Y-TZP). The role of the added yttria is to stabilize the crystal structure transformation during firing at elevated temperatures and to improve the physical properties of zirconia [1]. Yttria-stabilized zirconia is widely used as a dental biomaterial in prosthodontic frameworks because of its

C. Y. K. Lung • J. P. Matinlinna $(\bowtie)$

Dental Materials Science, Faculty of Dentistry,

The University of Hong Kong,

34 Hospital Road, Sai Ying Pun,

Hong Kong SAR, People's Republic of China

e-mail: jpmat@hku.hk high flexural strength (reported in the literature as 900 $1200 \mathrm{MPa}$ ) compared with other common ceramic materials such as alumina and base metal alloys such as Co-Cr [2]. Dental zirconia is a dense ceramic biomaterial that has a compression resistance of about 2,000 $\mathrm{MPa}$ [3]. Moreover, many investigations on the biocompatibility of yttria-modified zirconia have reported no cytotoxic effects on in vitro cell cultures [4] and no adverse in vivo tissue reactions in animals [5]. However, the bonding between zirconia and resin cement is relatively weak owing to the extremely inert character of zirconia. Derand et al. [6] reported that the shear bond strength between yttrium-stabilized zirconia and composite, without any pretreatment of the zirconia surface, was only about 1.5 MPa. For samples pretreated with micro pearls of low fusing porcelain and fired at $720{ }^{\circ} \mathrm{C}$ and some of them were further treated with silane, the shear bond strengths were 11.3 and 18.4 MPa, respectively, which were much higher than the samples without any treatment. The results revealed that the surface should be pretreated.

It is well understood that functional silane coupling agents have to be activated by hydrolysis before they can react with the substrate, via $-\mathrm{OH}$ groups on the substrate surface. Plueddemann and Clark $[7,8]$ reported that silane coupling agents were effective at significantly promoting adhesion between inorganic substrates such as metals, metal oxides, glass, silicates and organic matrices, including various plastics that are reinforced by fillers, whiskers and fibers. A complex but labile 3D silane film forms during the bonding of the dissimilar matrices to each other. The bonding strength between dental resin-composite cement and zirconia is increased by chemical bonds that form between the silica-coated zirconia and the silane, after the hydrolysis of the silane monomer to form silanol ( $=\mathrm{Si}-$ $\mathrm{OH})$. As a suggested pretreatment procedure, the zirconia surface must be silica-coated [9], because intaglio zirconia 
Table 1 Materials used in this study

\begin{tabular}{llll}
\hline Materials & Manufacturer & Purity/\% & Lot. No. \\
\hline Zirconia $\left(\right.$ Procera $^{\mathrm{TM}}$ ) & Nobel-Biocare, Sweden & N/A & N/A \\
3-isocyanatopropyltrimethoxysilane & Gelest, USA & 95 & $5 \mathrm{I}-7514$ \\
3-isocyanatopropyltriethoxysilane & Gelest, USA & 95 & $9 \mathrm{E}-14595$ \\
bis-1,2-(triethoxysilyl)ethane & Gelest, USA & N/A & $5 \mathrm{~L}-7926$ \\
Rocatec Sand Soft & 3M ESPE, Germany & $30 \mu \mathrm{m}$ silica-coated alumina \\
Deionized water & Millipore, Bedford, Massachusetts, USA & Resistivity 18.2 MS cm & 353587 \\
Ethanol & Riedel-de Haën, Germany & 99.8 & N/A \\
Rely X Unicem Aplicap resin cement & 3M ESPE, Germany & N/A & 03550 \\
3M ESPE Sil-silane & 3M ESPE, Germany & $<3 \%$ 3-methacryloxypropyltrimethoxysilane & 259583 \\
\hline
\end{tabular}

is inert and does not react with silanes. Silica-coating can be performed in dentist's office with a special sand-blasting system using Rocatec Sand Soft (a silica-coated alumina sand with an average particle diameter of $30 \mu \mathrm{m}$ ). This sand-blasting concept is widely used also in dental laboratories and applied in prosthetic dentistry. The technique is based on the principle that silica-coated alumina sand particles become anchored to the substrate surface, be it metal, alloy, amalgam, resin-composite or ceramic material. The sand particles on the surface bond as a very thin ceramic-like coating, which is why this method is sometimes called ceramic coating; it is more frequently known as silica-coating. Sandblasting also increases the surface roughness of zirconia and thus modifies its topology, which enhances the wetting of the silica-coated surface with silane during silanization [10].

Known applications of 3-isocyanatopropyltriethoxysilane include the functionalization of $\beta$-cyclodextrin for cholesterol removal from milk [11] and as a coupling agent for UVcurable epoxyacrylate resin to improve their mechanical properties in protective coatings [12]. Matinlinna et al. [13] demonstrated that isocyanatosilane achieved a significantly<smiles>CO[Si](C)(CCCN=C=O)OC</smiles><smiles>CCO[Si](CCCN=C=O)(OCC)OCC</smiles><smiles>CCO[Si](CC[Si](OCC)(OCC)OCC)(OCC)OCC</smiles>

III

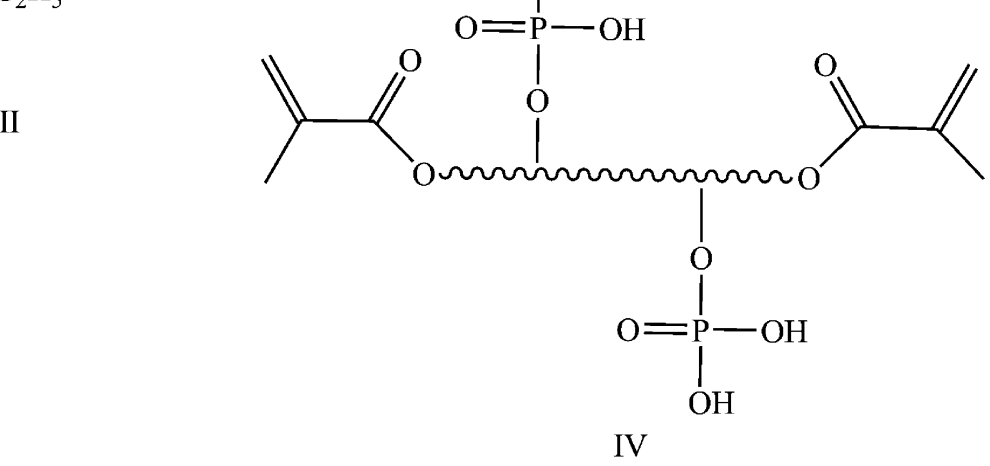

Fig. 1 The molecular structures of the two isocyanatosilanes, cross-linking silane and reactive monomer in resin-composite. I: 3isocyanatopropyltrimethoxysilane, II: 3-isocyanatopropyltriethoxysilane, III: bis-1,2-(triethoxysilyl)ethane and IV: reactive monomer in resin-composite 
Table 2 Mean shear bond strength of ICMS and ICS with or without addition of cross-linking silane (BTSE). Key: ICMS: 3isocyanatopropyltrimethoxysilane, ICS: 3-isocyanatopropyltriethoxysilane, BTSE: bis-1,2-(triethoxysilyl)ethane

\begin{tabular}{|c|c|c|c|c|c|}
\hline Silane & $\begin{array}{l}\text { Mean shear bond } \\
\text { strength } \pm \mathrm{SD} / \mathrm{MPa}\end{array}$ & $\begin{array}{l}\text { Coefficient } \\
\text { of variation }\end{array}$ & $\begin{array}{l}\text { Cohesive } \\
\text { failure } / \%\end{array}$ & $\begin{array}{l}\text { Mixed } \\
\text { failure/\% }\end{array}$ & $\begin{array}{l}\text { Adhesive } \\
\text { failure } \% \%\end{array}$ \\
\hline ICS $(0.1$ vol $\%)$ & $6.8 \pm 3.2$ & 47.3 & 0 & 13.3 & 86.7 \\
\hline ICS (1.0 vol\%) & $6.6 \pm 2.2$ & 33.0 & 0 & 0 & 100 \\
\hline ICS $(0.1$ vol \%) + BTSE (0.05 vol\%) & $6.0 \pm 1.9$ & 31.5 & 6.7 & 20 & 73.3 \\
\hline ICS $(1.0$ vol $\%)+$ BTSE $(0.5$ vol\%) & $7.2 \pm 3.1$ & 43.1 & 13.3 & 23.3 & 73.3 \\
\hline ICMS (0.1 vol\%) & $7.4 \pm 1.7$ & 22.5 & 6.7 & 13.3 & 80 \\
\hline ICMS (1.0 vol\%) & $6.6 \pm 2.6$ & 39.2 & 0 & 13.3 & 86.7 \\
\hline ICMS $(0.1$ vol \%) + BTSE (0.05 vol\%) & $9.5 \pm 2.6$ & 26.9 & 6.7 & 20 & 73.3 \\
\hline ICMS (1.0 vol \%) + BTSE (0.5 vol\%) & $9.2 \pm 3.9$ & 42.8 & 6.7 & 20 & 73.3 \\
\hline 3M ESPE silane & $8.8 \pm 1.4$ & 16.0 & 6.7 & 13.3 & 80 \\
\hline
\end{tabular}

higher shear bond strength specifically the adhesion between silicatized titanium and an experimental resin based on bisphenol-A-diglycidyldimethacrylate (bis-GMA), than 3methacryloxypropyltrimethoxysilane. It should be emphasized that water is always present in the interface of the silane (siloxane) film and silicatized zirconia surface under ambient humidity [8]. Water molecules can penetrate freely into the siloxane network and form hydrogen bonds among the polar functional groups. This process results in a reduction in thermal stability and polymer plasticization [14]. The amount of water adsorbed varies with the relative humidity of the environment.

The aim of this study, as an extension of some previous work [13], was to investigate the effects of varying hydrolyzable groups of isocyanatosilanes and silane concentrations, as well as the effect of adding a cross-linking silane, on the shear bond strength of a modern resin-composite attached to silicatized zirconia. The specimens were stored and tested in dry conditions under ambient humidity at room temperature to investigate the initial bond strength. The hypothesis of this in vitro study was that differences in bond shear strength would result from different alkoxy group types and by blending the functional silane.

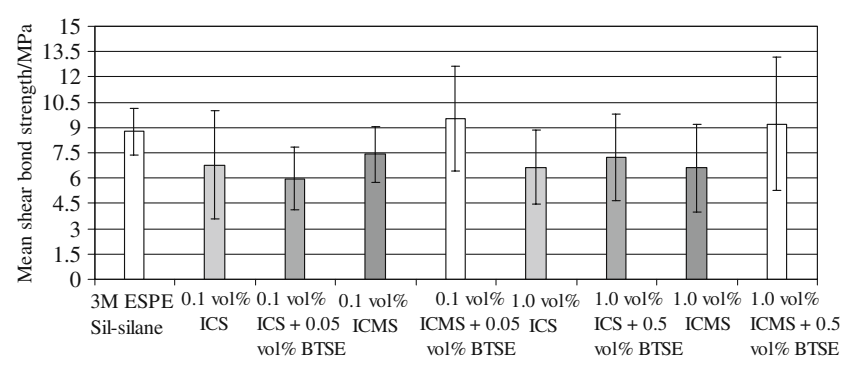

Fig. 2 Mean shear bond strengths of silicatized and silanized zirconia of control group and at two different concentrations of ICS and ICMS with cross-linking silane added. Key: ICS $=3$ isocyanatopropyltriethoxysilane, BTSE = bis-1,2-(triethoxysilyl) ethane, ICMS = 3-isocyanatopropyltrimethoxysilane

\section{Materials and Methods}

The materials used in this study are listed in Table 1. A square-shaped zirconia specimen with a surface area of about $10 \mathrm{~mm} \times 10 \mathrm{~mm}$ was embedded in cylinder-shaped plastic mold filled with PMMA acrylic resin. 15 specimens were prepared for each study group with a total of 135 specimens for 9 study groups. The two isocyanatosilanes in this study were 3-isocyanatopropyltrimethoxysilane and 3isocyanatopropyltriethoxysilane. The cross-linking silane used was bis-1,2-(triethoxysilyl)ethane. The molecular structures of the silanes and the reactive monomer present in the resin-composite cement are shown in Fig. 1.

\subsection{Preparation of Silica-coated Zirconia}

The surfaces of the zirconia specimens were first polished with 400-grit silicon carbide paper under running water. They were then cleaned ultrasonically (Decon Ultrasonics Ltd, Hove Sussex, England) for $10 \mathrm{~min}$ in deionized water and rinsed with $70 \%$ ethanol. After the specimens were allowed to dry at room temperature, their surfaces were sandblasted with 3M ESPE Rocatec Sand Soft (particle size, $30 \mu \mathrm{m}$ ) at a constant pressure of $280 \mathrm{kPa}$ for $30 \mathrm{~s} / \mathrm{cm}^{2}$ and at a perpendicular distance of $10 \mathrm{~mm}$. The specimens were transferred to a beaker filled with $70 \%$ ethanol and cleaned ultra-sonically for $10 \mathrm{~min}$ and then rinsed with $70 \%$ ethanol. The specimens were allowed to air-dry at room temperature for $1 \mathrm{~h}$. All specimens were prepared by one operator.

\subsection{Preparation of Silane Solution and Silanized Zirconia}

A solvent mixture of 95 vol\% absolute ethanol and 5 vol\% deionized water was prepared and its $\mathrm{pH}$ was adjusted to 4.5 with $1 \mathrm{M}$ acetic acid. It was allowed to stabilize for at least $24 \mathrm{~h}$ at about $7{ }^{\circ} \mathrm{C}$ (in a refrigerator) before use. The preparation procedure for the silane solution has been 
Table 3 ANOVA: single-factor analysis of 0.1 vol\% ICMS with cross-linking silane. Key for Tables 3, 4, 5, 6, 7, 8, and 9: ICS = 3isocyanatopropyltriethoxysilane, ICMS $=3$-isocyanatopropyltrimethoxysilane, BTSE $=$ bis-1,2-(triethoxysilyl)ethane

\begin{tabular}{llllll}
\hline Silane & Count & Sum & Average & Variance & \\
0.1 vol\% ICMS & 15 & 111.19 & 7.412667 & 2.79895 & \\
0.1 vol\% ICMS + 0.05 vol\% BTSE & 15 & 142.82 & 9.521333 & 6.577584 & $F$ crit \\
Source of variation & SS & df & MS & $F$ & 4.195982 \\
Between groups & 33.34856 & 1 & 33.34856 & 7.113197 & 0.012572 \\
Within groups & 131.2715 & 28 & 4.688267 & & \\
Total & 164.62 & 29 & & & \\
\hline
\end{tabular}

Table 4 ANOVA: single factor analysis of 1.0 vol\% ICMS with cross-linking silane

\begin{tabular}{llllll}
\hline Silane & Count & Sum & Average & Variance & \\
1.0 vol\% ICMS & 15 & 98.8 & 6.586667 & 6.663952 & \\
1.0 vol\% ICMS and 0.5 vol\% BTSE & 15 & 138.1 & 9.206667 & 15.5591 & $P$-value \\
Source of variation & SS & df & MS & $F$ & 0.040122 \\
Between groups & 51.483 & 1 & 51.483 & 4.633298 & 4.195982 \\
Within groups & 311.1227 & 28 & 11.11152 & & \\
Total & 362.6057 & 29 & & & \\
\hline
\end{tabular}

Table 5 ANOVA: single-factor analysis of 0.1 vol $\%$ ICS with cross-linking silane

\begin{tabular}{lllllc}
\hline Silane & Count & Sum & Average & Variance & \\
0.1 vol\% ICS & 15 & 101.79 & 6.786 & 10.32104 & \\
0.1 vol\% ICS + 0.05 vol\% BTSE & 15 & 89.54 & 5.969333 & 3.540592 & $F$ crit \\
Source of variation & SS & df & MS & $F$ & 4.195982 \\
Between groups & 5.002083 & 1 & 5.002083 & 0.721716 & 0.402787 \\
Within groups & 194.0629 & 28 & 6.930816 & & \\
Total & 199.0649 & 29 & & & \\
\hline
\end{tabular}

Table 6 ANOVA: single-factor analysis of 1.0 vol\% ICS with cross-linking silane

\begin{tabular}{lllllc}
\hline Silane & Count & Sum & Average & Variance & \\
0.1 vol\% ICS & 15 & 99.6 & 6.64 & 4.810229 & \\
0.1 vol\% ICS + 0.05 vol\% BTSE & 15 & 108.24 & 7.216 & 9.659997 & $F$ crit \\
Source of variation & SS & df & MS & $F$ & 0.562272 \\
Between groups & 2.48832 & 1 & 2.48832 & 0.343923 & 4.195982 \\
Within groups & 202.5832 & 28 & 7.235113 & & \\
Total & 205.0715 & 29 & & & \\
\hline
\end{tabular}


Table 7 ANOVA: single-factor analysis of control silane, 0.1 vol $\%, 1.0$ vol $\%$ of ICS and ICMS

\begin{tabular}{llllll}
\hline Silane & Count & Sum & Average & Variance \\
3M ESPE silane & 15 & 131.37 & 8.758 & 1.965531 & 7.994607 \\
0.1 vol\% ICS & 15 & 91.96 & 6.130667 & 2.79895 \\
0.1 vol\% ICMS & 15 & 111.19 & 7.412667 & 4.810229 & P-value \\
1.0 vol\% ICS & 15 & 99.6 & 6.64 & 6.663952 & 0.015574 \\
1.0 vol\% ICMS & 15 & 98.8 & 6.586667 & $F$ & 2.502659 \\
Source of variation & SS & df & MS & & \\
Between groups & 63.91929 & 4 & 15.97982 & & \\
Within groups & 339.2658 & 70 & 4.846654 & & \\
Total & 403.185 & 74 & & & \\
\hline
\end{tabular}

described elsewhere [15]. Concentrations of $0.1 \mathrm{vol} \%$ and 1.0 vol\% of 3-isocyanatopropyltrimethoxysilane and 3isocyanatopropyltriethoxysilane in the solvent mixture were prepared in a $25 \mathrm{~mL}$ volumetric glass flask. The silane primers were allowed to hydrolyze for $1 \mathrm{~h}$ at room temperature [16].

The cross-linking silane at concentrations of $0.05 \mathrm{vol} \%$ and $0.5 \mathrm{vol} \%$ in the solvent mixture were separately allowed to hydrolyze for $23 \mathrm{~h}$. The two functional silane coupling agent monomers were then added, corresponding to a final functional silane concentration of $0.1 \mathrm{vol} \%$ and $1.0 \mathrm{vol} \%$. The silane primer was then allowed to hydrolyze for 1 additional hr [17].

The silane solution was applied onto the surface of each zirconia specimen with a new fine brush each time, and allowed to react and dry for $5 \mathrm{~min}$ on the zirconia surface. 3M ESPE Silsilane was used as a control; this is commonly used in the dental clinic and is a pre-hydrolysed silane product that has one functional silane, 3-methacryloxypropyltrimethoxysilane, at a silane content of about $1 \mathrm{vol} \%$ to $2 \mathrm{vol} \%$.

\subsection{Procedure to Bond Resin Cement to Silica-coated and Silanized Zirconia}

RelyX resin cement (a so-called universal dental resincomposite cement) from 3M ESPE was activated according to manufacturer's instructions and transferred to a highfrequency mixing unit (Silamat, Ivoclar Vivadent, Schaan, Liechtenstein) for $15 \mathrm{~s}$. The resin-composite cement was transferred to a cylindrical polyethylene mold with a diameter of $3.7 \mathrm{~mm}$ and height of $4.0 \mathrm{~mm}$, which was held firmly in place on the surface of the zirconia. The resin-composite cement stub, with an average height of $4.0 \mathrm{~mm}$, was light cured for $40 \mathrm{~s}$ using a light-curing unit (Elipar 2500 Halogen Curing Light, 3M ESPE), from the top and at the contact area between the resin-composite and silicatized and silanized zirconia. The wavelength ranged from $400 \mathrm{~nm}$ to $500 \mathrm{~nm}$ and the light intensity was $1,300 \mathrm{~mW} / \mathrm{cm}^{2}$. The mold was carefully removed by pressing the stub gently with an instrument while the mold was lifted upwards. The specimens were kept in a desiccator for $24 \mathrm{~h}$ before shear bond strength testing.

\subsection{Shear Bond Strength Testing}

The zirconia specimen with the light-cured resin-composite stub was mounted on the materials testing instrument (Instron LTD, Model 1185, Norwood, MA). A load of $1,000 \mathrm{~N}$ was applied at a cross-head speed of $1.0 \mathrm{~mm} / \mathrm{min}$ [15] until failure occurred. The shear bond strength was calculated by the formula: $\delta=\mathrm{F} / \mathrm{A}$ where $\mathrm{F}$ is the force at failure and $\mathrm{A}$ is the cross-sectional area of the stub.

\subsection{Failure Type Analysis}

The modes of failure of the tested groups were assessed visually by light microscopy and classified according to the amount of resin stub remaining on the zirconia surface. When $1 / 3$ or less

Table 8 ANOVA: single-factor analysis of 0.1 vol $\%$ and $1.0 \mathrm{vol} \%$ of ICS

\begin{tabular}{llllll}
\hline Silane & Count & Sum & Average & Variance & \\
0.1 vol\% ICS & 15 & 101.79 & 6.786 & 10.32104 & \\
1.0 vol\% ICS & 15 & 99.6 & 6.64 & 4.810229 & $P$ crit \\
Source of variation & SS & df & MS & $F$ & 0.885464 \\
Between groups & 0.15987 & 1 & 0.15987 & 0.021131 & 4.195982 \\
Within groups & 211.8378 & 28 & 7.565634 & & \\
Total & 211.9976 & 29 & & & \\
\hline
\end{tabular}


Table 9 ANOVA: single-factor analysis of $0.1 \mathrm{vol} \%$ and $1.0 \mathrm{vol} \%$ of ICMS

\begin{tabular}{llllll}
\hline Groups & Count & Sum & Average & Variance & \\
0.1 vol\% ICMS & 15 & 111.19 & 7.412667 & 2.79895 & \\
1.0 vol\% ICMS & 15 & 98.8 & 6.586667 & 6.663952 & $P$-value \\
Source of variation & SS & df & MS & $F$ & 0.307259 \\
Between groups & 5.11707 & 1 & 5.11707 & 1.081501 & 4.195982 \\
Within groups & 132.4806 & 28 & 4.731451 & & \\
Total & 137.5977 & 29 & & & \\
\hline
\end{tabular}

of the resin stub remained, the failure type was assigned as 'adhesive' and when the amount remaining was $>1 / 3$ but $<2 / 3$, it was classified as 'mixed'. When the amount remaining was $\geq$ $2 / 3$, it was classified as 'cohesive' failure [18].

\subsection{Scanning Electron Microscopy (SEM)}

SEM (XL30CP, Philips Electron Optics, Eindhoven, The Netherlands) analysis of the polished and silica-coated zirconia surfaces and resin bonding to zirconia after shear bond test was performed. The operational voltage was $10 \mathrm{kV}$. The vacuum pressure for measurement was $3.5 \times$ $10^{-5} \mathrm{~Pa}$. Tungsten filament was used for electron beam generation. The secondary electron detector was used for detecting the secondary electron signals.

\subsection{Statistical Analysis}

Analysis ToolPak in Microsoft Office Excel 2003 (Microsoft Corporation) was used for the statistical analysis of the collected data. The mean shear bond strengths of tested groups were analyzed by ANOVA with mean shear bond strength as the dependent variable and concentration, type of silane and addition of cross-linking silane as independent variables. A $p$ value $<0.05$ was taken as being statistically significant.

\section{Results and Discussion}

The results for all mean shear bond strengths measured for 3-isocyanatopropyltrimethoxysilane and 3- isocyanatopropyltriethoxysilane with and without the addition of the cross-linking silane (bis-1,2-(triethoxysilyl) ethane) in dry conditions are summarized in Table 2 and Fig. 2. ANOVA analysis (Tables 3, 4, 5, 6, 7, 8, and 9) revealed that there were no significant differences in the mean shear bond strengths between $0.1 \mathrm{vol} \%$ and $1.0 \mathrm{vol} \%$ concentrations of 3-isocyanatopropyltrimethoxysilane ( $p=$ $0.307)$ and 3-isocyanatopropyltriethoxysilane $(p=0.885)$. There were also no significant differences in the mean shear bond strengths between 3-isocyanatopropyltrimethoxysilane and 3-isocyanatopropyltriethoxysilane at concentrations of $0.1 \mathrm{vol} \%(p=0.205)$ and $1.0 \mathrm{vol} \%(p=0.952)$. However, there were significant differences between the control group, 0.1 vol $\%$ and $1.0 \mathrm{vol} \%$ for 3-isocyanatopropyltrimethoxysilane $(p<$ $0.02)$ and for 3-isocyanatopropyltriethoxysilane $(p<0.04)$. There were significant differences in shear bond strengths after cross-linking silane had been added, both for 0.1 vol\% 3-isocyanatopropyltrimethoxysilane $(p<$ 0.01 ) and 1.0 vol\% 3-isocyanatopropyltrimethoxysilane $(p<0.04)$. In contrast, there were no significant differences in mean shear bond strengths after cross-linking silane had been added to 3-isocyanatopropyltriethoxysilane at $0.1 \mathrm{vol}$ $\% \quad(p=0.403)$ or 1.0 vol\% $(p=0.562)$. There was no significant difference between the control group and 3isocyanatopropyltrimethoxysilane at $0.1 \mathrm{vol} \%(p=0.320)$ or $1.0 \mathrm{vol} \%(p=0.681)$ with cross-linking silane added, but there were significant differences between the control group and 3-isocyanatopropyltriethoxysilane at $0.1 \mathrm{vol} \%$ $\left(p<8 \times 10^{-5}\right)$ or 1.0 vol\% $(p<0.009)$ with crosslinking silane added. There was also a significant difference between the control group, 0.1 vol\% and

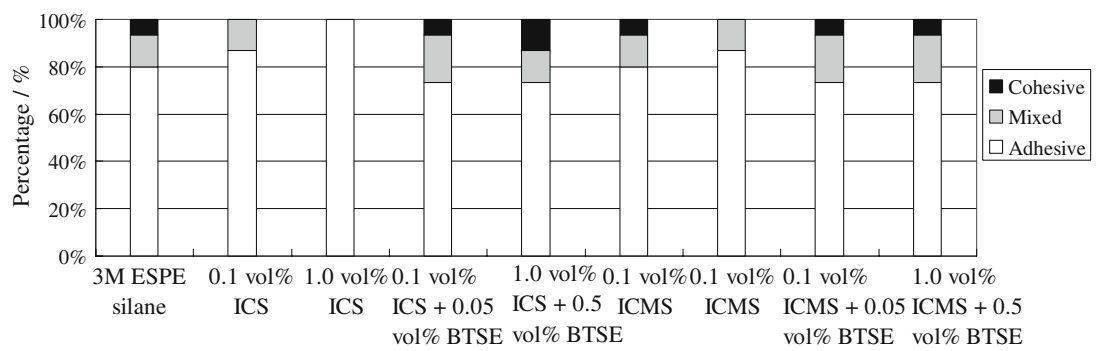

Fig. 3 Percentage modes of failure of nine tested groups. Key: ICS $=3$-isocyanatopropyltriethoxysilane, BTSE $=$ bis-1,2-(triethoxysilyl)ethane, ICMS = 3-isocyanatopropyltrimethoxysilane 


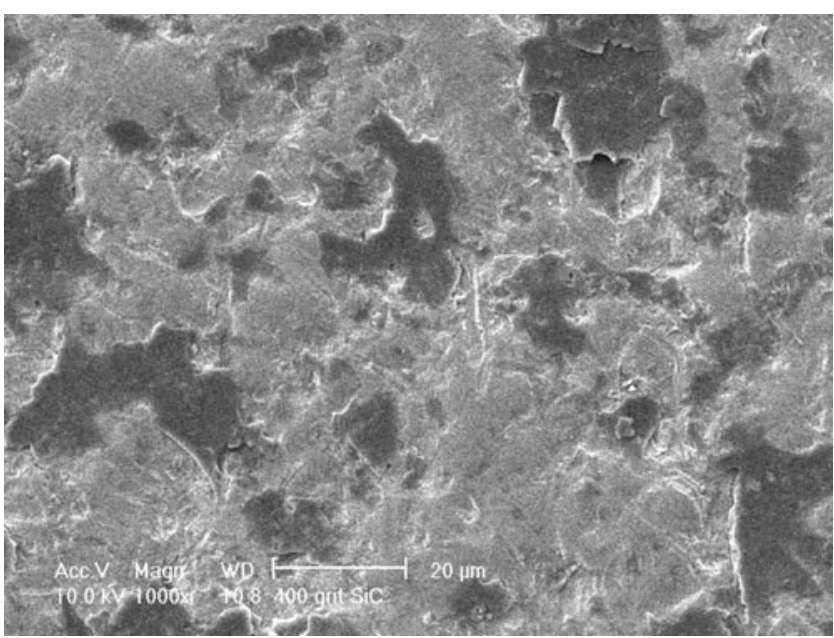

Fig. 4 Zirconia surface by polishing (SEM image, magnification $1,000 \times)$

1.0 vol\% 3-isocyanatopropyltriethoxysilane and 3isocyanatopropyltrimethoxysilane $(p<0.02)$. The failure mode assessment is presented in Table 2. A bar-chart diagram summarizing the results of the failure mode assessment is shown in Fig. 3.

The SEM analysis of the images of the polished zirconia surface (Fig. 4) and the silica-coating zirconia surface (Fig. 5) showed some differences. It can be seen clearly from Fig. 5, that the silica-coated alumina particles were finely divided depositing on the polished zirconia surface. Figure 6 showed silica-coated zirconia surface and silanized with 0.1 vol\% ICMS and with light-cured RelyX resin cement residue after shear bond test.

This study of the chain length of the hydrolyzable groups of two isocyanatosilanes on the shear bond strength of silicatized zirconia revealed that the rate of hydrolysis is slower the more bulkier the hydrolyzable alkoxy group is. The hydrolysis of the

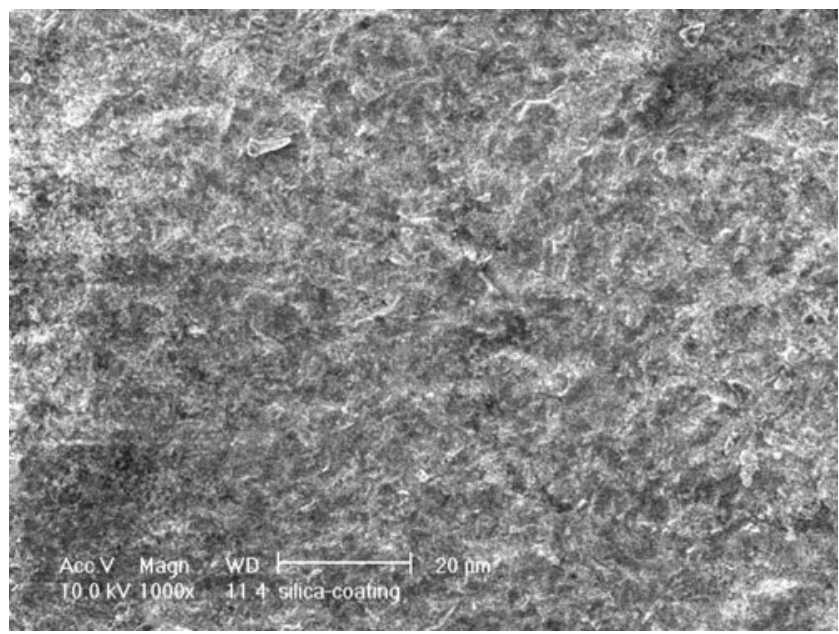

Fig. 5 Silica-coated zirconia surface (SEM image, magnification $1,000 \times)$

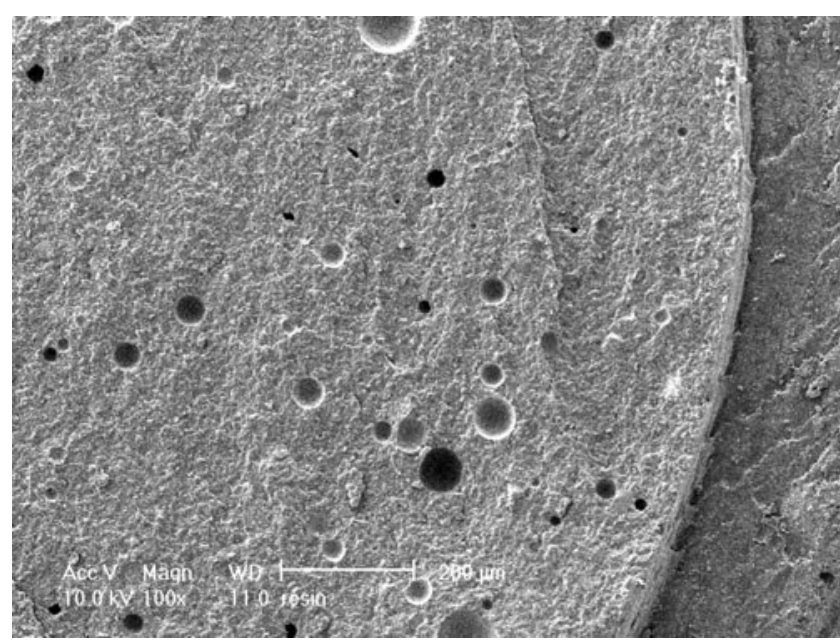

Fig. 6 RelyX resin cement residue left on the zirconia surface after shear bond test (SEM image, magnification $100 \times$ )

silane takes place by a bimolecular nucleophilic substitution $\left(\mathrm{S}_{\mathrm{N}} 2\right)$ reaction at the silicon atom [19], in which there is nucleophilic backside attack of the central silicon atom in the silane backbone. A new bond is formed between the nucleophile and the silicon, while a bond is broken between the leaving group (alcohol) and silicon. The rate of hydrolysis for 3-isocyanatopropyltrimethoxysilane is thus faster than for 3-isocyanatopropyltriethoxysilane, because methoxy groups hydrolyze at a rate that is approximately 10 times that of ethoxy groups. Therefore, the mean shear bond strength value for the former is greater than for the latter, although the difference is statistically insignificant.

The addition of a cross-linking silane to form a blend with a functional silane enhanced the bonding of resin to zirconia. This was statistically significant for the tested groups for 3-isocyanatopropyltrimethoxysilane $(0.1 \mathrm{vol} \%(p<0.01)$ and $1 \mathrm{vol} \%(p<0.04))$ but it was

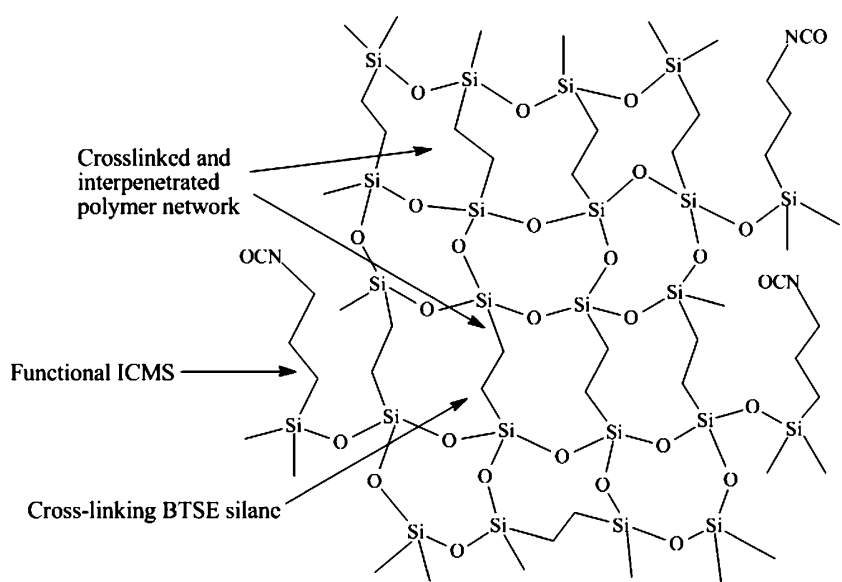

Fig. 7 Incorporation of a cross-linking silane with an organofunctional silane forming an interpenetrating cross-linking polymeric network. Key: ICMS $=3$-isocyanatopropyltrimethoxysilane, $\mathrm{BTSE}=$ bis-1,2-(triethoxysilyl)ethane 


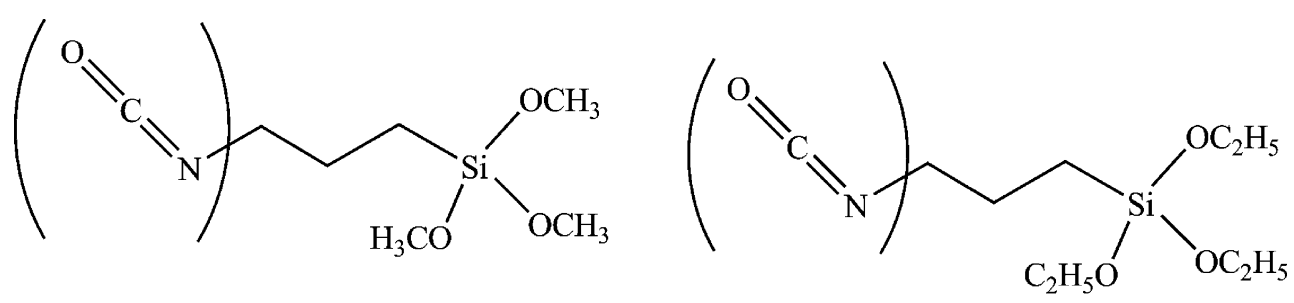

I

II

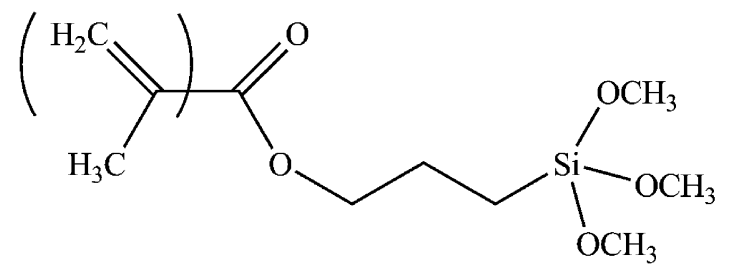

III

Fig. 8 The organofunctional groups in I: 3-isocyanatopropyltrimethoxysilane and II: 3-isocyanatopropyltriethoxysilane is -NCO, and in III: 3methyacryloxypropyltrimethoxysilane is $>\mathrm{C}=\mathrm{C}<$. Organofunctional groups are highlighted in brackets

statistically insignificant for the tested groups of 3isocyanatopropyltriethoxysilane $(0.1 \quad \mathrm{vol} \% \quad(p=0.403)$ and $1.0 \mathrm{vol} \%(p=0.562))$. Incorporation of a cross-linking silane with an organofunctional silane supposedly forms an interpenetrating cross-linking polymeric network with the siloxane film (Fig. 7) [20], which is understood to increase the interlocking nature of the whole network, such that a larger force is required to break it (Tables 3, 4, 5, and 6).

The two silane concentrations of $0.1 \mathrm{vol} \%$ and $1.0 \mathrm{vol} \%$ revealed a higher shear bond strength for the lower concentration, although the result was statistically insignificant, viz. $p=0.307$ for 3-isocyanatopropyltrimethoxysilane and $p=0.885$ for 3 -isocyanatopropyltriethoxysilane. Park and Jang [21] have suggested that physisorbed silane layers formed on the chemisorbed layer because of an excess amount of unreacted (unhydrolyzed) silane at a relatively high concentration. This layer can be thought to act as a lubricant or deformable layer. Therefore, fracture and failure will tend to occur in this region through the slippage of physisorbed silane layers. According to Table 2, the proportion of failures for $0.1 \mathrm{vol} \%$ 3-isocyanatopropyltriethoxysilane and 3-isocyanatopropyltrimethoxysilane showing the adhesive mode of failure is lower than for 1.0 vol\% (c.f. Fig. 4). This observation is in agreement with the findings of Park and Jang [21], who concluded that fracture occurs at the interface between the resin cement and zirconia (adhesive type of failure) at higher silane concentrations and within the resin cement (cohesive failure) at lower concentrations (Tables 8 and 9).

The shear bond strength measured for the control group silanized with 3-methacryloxypropyltrimethoxysilane (control) was higher than the 3-isocyanatopropyltriethoxysilane and 3isocyanatopropyltrimethoxysilane groups. This effect may be largely because of the organofunctional groups of the silane, which are prone to react with functional groups in RelyX Unicem resin composite cement (see Fig. 1). The organofunctional group in 3-methacryloxypropyltrimethoxysilane is $>\mathrm{C}=\mathrm{C}<$, whereas in 3-isocyanatopropyltriethoxysilane and 3isocyanatopropyltrimethoxysilane it is -NCO (Fig. 8), with the carbon-carbon double bond being more reactive than -NCO towards the functional group in RelyX Unicem resin (Table 7). This property will be discussed in more detail in the second paper related to this study see, "Part II: Mechanistic Approach".

Finally, the standard deviation varied between different test groups. A low standard deviation for the control group might be explained by the fact that the silane used in this study was prehydrolyzed. Furthermore, the arbitrary character of sand-blasting the zirconia surface during silicacoating cannot be easily assessed.

The effect of short-term and long-term water storage of the specimens, i.e. the silicatized zirconia silanized with two isocyanato silanes, will be carried out in the near future to assess the different hydrolytic effects on silane-aided bonding, again using the two isocyanate silanes alone and in blends with a cross-linking silane.

\section{Conclusions}

In this in vitro study carried out under ambient conditions, the following conclusions might be drawn:

1. The effect of differing sizes of hydrolyzable alkoxy groups in two silanes on the bonding of resin to zirconia was statistically insignificant. 
2. The addition of cross-linking silane to a functional silane enhanced the bonding strength between resin and zirconia for the tested groups of 3-isocyanatopropyltrimethoxysilane but not for 3-isocyanatopropyltriethoxysilane.

3. The shear bond strength was higher for 3methacryloxypropyltrimethoxysilane (control) than for 3-isocyanatopropyltriethoxysilane and 3-isocyanatopropyltrimethoxysilane.

Acknowledgments This work was financially supported from the research grants of The University of Hong Kong (Seed Funding Programme for Basic Research 200905159006). The authors wish to thank Dr. Barry Arkles from Gelest Inc, USA, for generously providing silane coupling agent monomers to our study. Dr. Trevor Lane is warmly acknowledged for proofreading this paper.

Open Access This article is distributed under the terms of the Creative Commons Attribution Noncommercial License which permits any noncommercial use, distribution, and reproduction in any medium, provided the original author(s) and source are credited.

\section{References}

1. Richard MP (2007) Dentistry Today $3: 114$

2. Piconi C, Maccauro G (1999) Biomaterials 20:1
3. Manicone PF, Iommetti PR, Raffaelli L (2007) J Dent 35:819

4. Dion I, Bordenave L, Lefebvre F, Bareille R, Baquey C (1994) J Mater Sci Mater Med 5:18

5. Christel P, Meunier A, Heller M, Torre JP, Peille CN (1989) J Biomed Mater Res 23:45

6. Derand T, Molin M, Kvam K (2005) Dent Mater 21:1158

7. Plueddemann EP (1968) J Paint Technol 40:1

8. Clark HA, Plueddemann EP (1963) Plastics 40:133

9. Tashkandi E (2009) The Saudi Dent J 21:113.

10. Meiners H, Herrmann R, Spitzbarth S (1990) Dent Labor 38:185

11. Kwak HK, Kim SH, Kim JH, Choi HJ, Kang J (2004) Arch Pharm Res 27:873

12. Kahraman MV, Kugu M, Menceloglu Y, Kayaman-Apohan N, Gungor A (2006) J Non-Crystalline Solids 352:2143

13. Matinlinna JP, Lassila LVJ, Kangasniemi I, Vallittu PK (2005) J Dent Res 84:360

14. Oyagüe RC, Monticelli F, Toledano M, Osorio E, Ferrari M, Osorio R (2009) Dent Mater 25:392

15. Matinlinna JP, Lassila LVJ, Kangasniemi I, Yli-Urpo A, Vallittu PK (2005) Dent Mater 21:287

16. Aboushelib MN, Matinlinna JP, Salameh Z, Ounsi H (2008) Dent Mater 24:1268

17. Matinlinna JP, Lassila LVJ, Vallittu PK (2006) J Dent 34:740.

18. Matinlinna JP, Lassila LVJ, Vallittu PK (2009) Silicon 1(4):249

19. Bento AP, Bickelhaupt FM (2007) J Org Chem 72:2201

20. Klempner D, Sperling LH, Utracki LA (1994) Interpenetrating polymer network. Advances in chemical sciences. Am Chem Soc, Washington, Vol. 239

21. Park R, Jang J (2004) J App Poly Sci 91:3730 